\title{
Assessment of UT (University of Tehran) change management in quality Orientation process based on ADKAR model
}

\author{
Akbariani, Saeed $^{\mathrm{a}}$; Farhadirad, Hamid $^{\mathrm{b}}$ and Abachian Ghassemi, Reza ${ }^{\mathrm{c}}$ \\ ${ }^{\mathrm{a}}$ Department of Management, Islamic Azad University, Iran , ${ }^{\mathrm{b}}$ Department of Psychology \\ and Educational, University of Shahid Chamran, Iran, ${ }^{\mathrm{c}}$ Department of Administrative \\ Sciences and Economics, University of Isfahan, Iran.
}

\begin{abstract}
In this paper quality orientation process of Tehran University was evaluated. For effective change human resource of organization must have five qualities: Awareness about need to change; Desire to make the change happen; Knowledge about how to change; Ability to change; Reinforcement to retain the changes. With these human resource qualities, work dimension (for example: structures and process of doing work) need to well set with planned changes. Work dimension had five main elements too: 1-business needs and opportunities 2- setting goals and boundaries 3-desining process and systems 4-devalope way to solve problems and 5-post-implementation. These research conclusions show that UT human resource, sense high need and desire to change in quality. So, to success in quality change sense high ability in self and their colleagues, and access to needed knowledge for change in quality of UT. But university's systems don't support these efforts so that proper low support for qualitative changes. In work dimension, quality improvement opportunities, goals, and needs weren't well defined. Furthermore systems and process of accepting quality weren't developed suitably. Solution sections had some problem too. Some solutions remain in design level only and others after implementation don't evaluate for distinguish weaknesses and strength.
\end{abstract}

Keywords: Change management-Quality of Higher education ADKAR Model-Tehran University. 


\section{Introduction}

In the 1970s and 1980s, many American firms experienced new challenge. This new challenge was competition with variety of obstinate competitors from Japan. Undeniably, many firms had lost the international competitive edge they had enjoyed in the 1950s and the inevitable result was declining market shares, sustained losses, unemployment, and massive soul-searching by firms. These challenges an international forces such as: increasing global competition and the struggle to survive, increasing costs, demands for accountability and rising customer expectations about quality, a number of US corporations such as Intel, Hewlett Packard, Xerox, IBM, Motorola, etc. undertook quality initiatives. Juran and Deming theory about quality that gave successful outcomes in Japan and other theories that deal with "Quality management" were considered highly by these firms. Higher education confronted with similar situation. Rapidly changing information technology, highly increasing costs and accountability, competition for best student and academic staff enrolment lead to higher education consideration get addressed to quality of teaching and other university's aspects (Venkatraman, 2007). Bingham (1993) in his paper states that the common mistakes made in implementing TQM in industry are lack of leadership, middle management muddle, misunderstanding of participation, obsession with process and failure to include the customer. He concludes that in higher education, TQM's long-term success depends on the lessons driven from industry. Conclusion of these new orientations and thinks was universities consideration to quality as a tool for maintenance in competitive environment. Must be said that, this process for success need to well managing. The first section starts on page two. incorporating all text, references, figures and tables. These guidelines are strict: papers failing to adhere to the guidelines (by being more than 8 pages, altering margins or not following the template) will be rejected without consideration of their merits Tehran University as an educational organization for fundamental change in all quality aspects had very high efforts; in fact on of the mental disturbance of this university is quality assurance system implementation. Establish of quality assessment center, UT science and technology PARK, try to development of internal evaluation culture, implement of continues evaluation system, establish total system for gathering information and so on are samples of this educational organization for fundamental change in its plans quality. So main problem in this research is change management of UT quality orientation that must be assessed based on ADKAR model (Bazargan, 1993).

Quality and higher education quality had some definitions, and any definition addressed especial aspects of this concept or sees it in a special view. Juran argued that every product that be easy for use, and consumers be satisfy from using it, that product have quality (Gourchian et al., 2003). According to international quality assurance network, higher education quality is: higher education conformity with appointed standards, missions, goals 
and expectations (Gourchian et al., 2003). In UNESCO view, higher education quality is a multi dimensional concept that related to environmental situation, university systems, and standards of educational system (UNESCO, 2007). Harvey and Green to quote from Bigges (2001) argued that quality had two kind definitions 1- Quality is matching with goal. Most important goal of universities is teaching and research that receiving students to effective learning and coordination with this goal is main criterion for university's quality assurance. 2- Quality is change factor. Quality of education do change learners perceptions of their environment, application ways of knowledge for solve real world problems, teachers' perceptions from their role into education and organizational culture. This continues changes in quality accepted when lead to more reforms (Gourchian et al., 2003).

Rangnes and Haraldsena (2007) argued that change in higher education quality need to change in seven contexts that are main quality improvement elements of higher education: Change in governance at the institutional level; Increased institutional autonomy; New funding for the institutions; New degree structure, that is bachelor and master programs; New forms of student guidance, evaluation and assessment; New financial support to students; Internationalization.

In the interim of theoretical and functional definitions of quality believed that quality is a multi form and multi dimensional concept and views, values and special goals of anybody or group form the main elements of quality definition. Then he classifies quality concepts that utilized in higher education into eight set that are as following: Descriptive quality; Quality in form of loyalty to traditions and customs; Quality in form of loyalty to missions; Quality in form of loyalty to improvement and perfection standards; Quality in form of consumers' satisfaction; Quality in form of to prove to be true of consumers goals; Quality in form of added value; Quality in form of continues improvement (Gourchian et al., 2003).

Tucker believed that in addition to these cases in real world, quality related to situation. And even it is possible that could define quality in higher education as expressing of students' critical thinking skills. Based on above proper a holistic definition for quality is very difficult and challengeable; because quality doesn't come from a total model or general theory, perhaps is a special situation of higher education system and output of set of functions that must be responsible for social needs at a special time. But it is true that quality in itself addressed accomplishment need, perception of situations and changes and planning for improvement. And for accomplishment to this special situation must define this desire situation and continually try to improve it.

UNESCO (2007) summarized quality of higher education elements into four following sets:

1-Innovation in curricula and programs teaching methods and aids, interdisciplinary;

2-Lifelong learning and the qualitative transformation;

3-Accreditation and evaluation; 


\section{4- Career guidance.}

Clery (1993) proposed one of the practical usages of quality management standards in higher education. His model is contains 20 orders to utilizing of ISO9000 standards.

\section{ADKAR model for change management (2006):}

Based on ADKAR model, for effective change management human resource of organization must have five main qualities: 1-Awarness: awareness about need to change2Desire: desire to make the change happen3-Kowledge: knowledge about how to cahnge4Ability: ability to cahnge5-Reinforcment: reinforcement to retain the changes. These five qualifications are necessity of organizational change. Organizational members must sense urgency and need about change and have knowledge and desire to do change and on the other hand organizational system must support these changes. Other dimension of change related to organizational work process. In this dimension first needs and opportunities for change must be defined and to receiving those solutions must be provide. And then solutions must be implemented and evaluated. Below figure shows combinations of these tow dimensions:

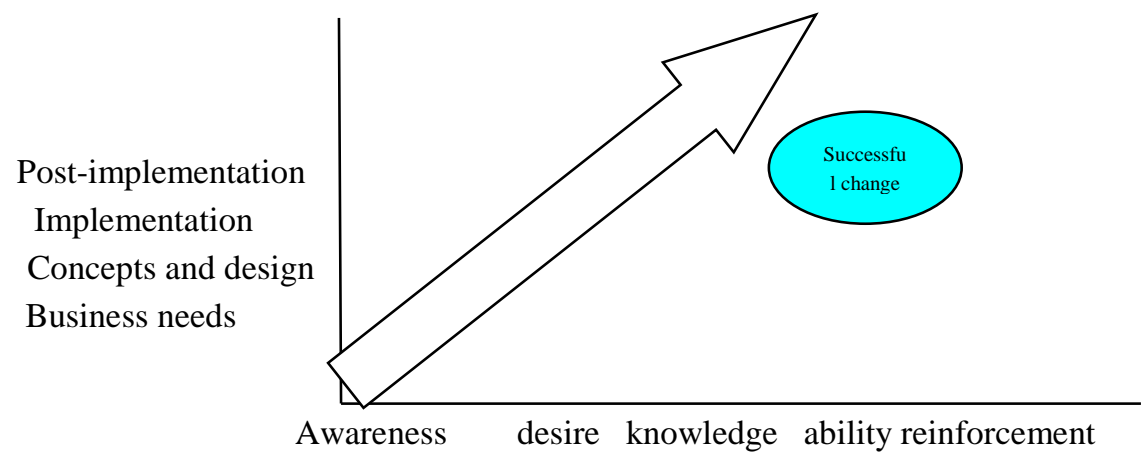

Figure 1. ADKAR a model for change management (2006)

\section{Resaerch Methodology}

This research is a descriptive one. Academic members of University of Tehran in 14 faculties are society of this research. These members are about 1530 persons. To gathering data in this research used a questioner that provided by researcher. This questioner has 25 question based on five dimensions of adkar model .For estimate validity and reliability of this instrument did a primarily test in a sample that had 30 members, and to validation test use formal validity. Estimated Cronbach $\alpha$ was $82 \%(\alpha=82 \%)$ that show this instruments is relatively reliable. Finally do an open interview with some of members to complete data gathering. 


\section{Findings}

Change in organization environment lead to change in organizational structure, needs, costumers, and so on. If organization want be active in this situation must be aware of these external dynamics and sense to use of these changes. Awareness is one of the change necessities. In a holistic view one of the successful change factors is that managers should percept philosophy of change and profitability of it (Kruger, 2007). The graph(1) that presented in below shows that research sample highly aware of quality of university and try to change and improve it.

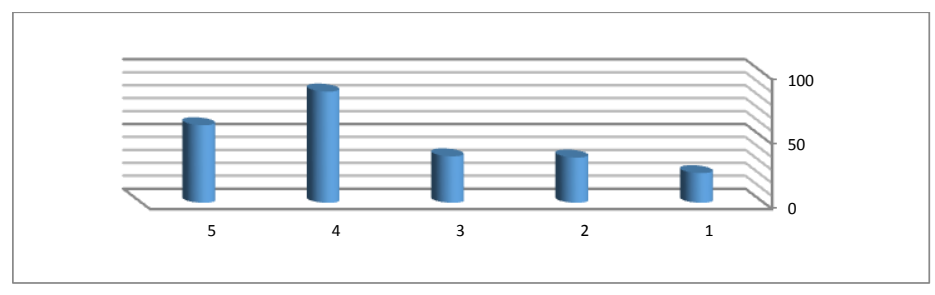

Figure 2. Awareness

Above figure shows that almost 61 percent of UT academic staff has sense need to change in quality of university and only 9 percent haven't the same senses or aren't aware of it. One of the basic necessities for change is motivated work force. Long term successful in any transformational or planned change related to desire of members to do change. Internal motivation for does change has three steps: establish a new perceptional structure, utilization and confirmation. If these steps be complete change could receive to the ends (Sarai, 1993). In this paper UT academic staff has high desire to change quality so that 69 percent of them have highly desire to participate in change in quality below graph show this matter.

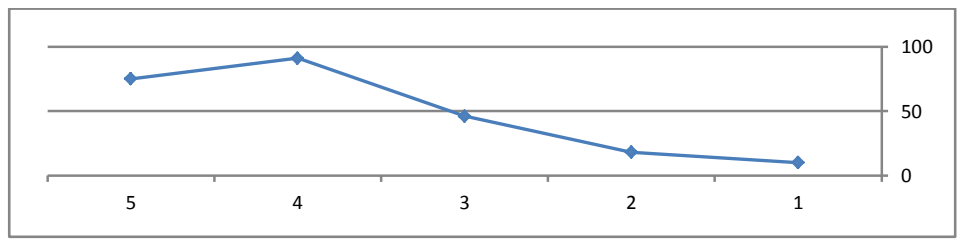

Figure 3. Desire

With regard to this figure we understand that only 4 percent of academic staff hasn't sufficient desire to change the quality.Employers that have sense of ability to do works with excitement, honor, and ownership sense work in organization; and in addition to responsibility have innovation and creativity in organization and preferred organizational interests on personal interests. To have enabler work force is an organizational preference and if this ability utilized in organization could be one source for many organizational 
preferences. In this research academic staff of UT has ability sense to change the quality of university.

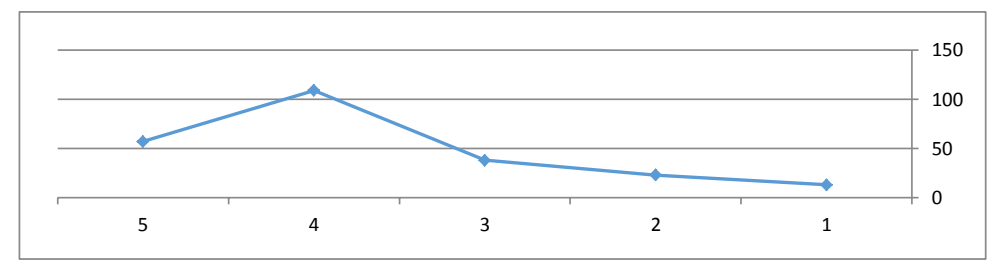

Figure 4. ability

This figure shows that research sample have very high ability for change in quality of university. Grasp updated knowledge is one of the effective factors that impact on success of change management. If we have been needed knowledge for change we could better deal with change and probability for successful is higher than when we haven't needed knowledge. In this research we understand that academic staff of UT has needed knowledge for change in quality of university.

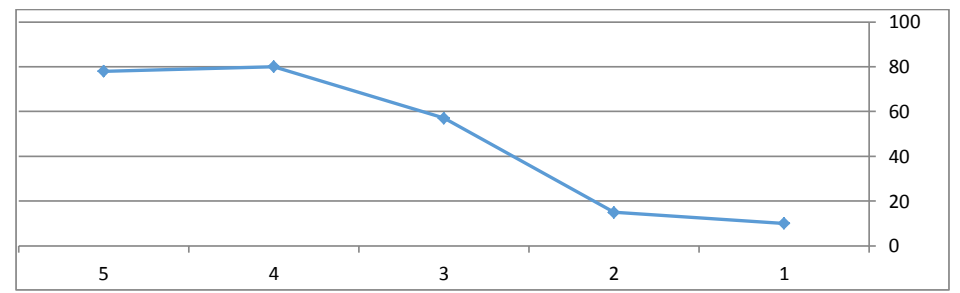

Figure 5. Knowledge

With regard to number four graph we see that sample have needed knowledge for change in quality of university. In addition to all factors that presented above for successful change management university systems must support changes. In other words if personal efforts that utilized for change didn't appreciate we couldn't have any expectation for successful and effective change process. In this research UT system don't efficient support for changes. Figure 5 show this matter.

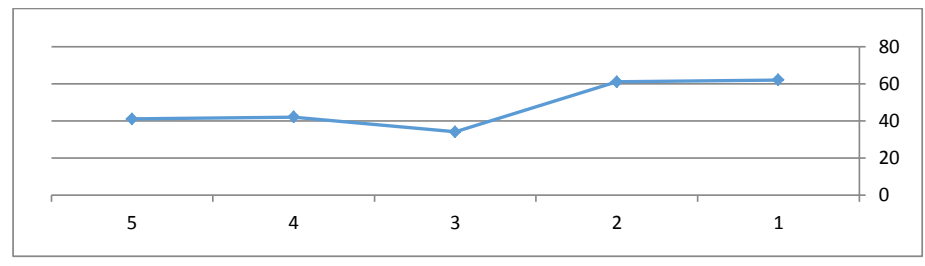

Figure 6. reinforcement 
Graph number 6 show combinative figure of these five main elements. This figure shows that only university systems aren't supporter for university change process. But other factors are sufficient for change in quality of UT. Humanistic factors that related to academic staffs of university are completely prepare to change in quality process. Figure 6 shows this matter clearly. If UT want to successes in quality change should use this capacity.

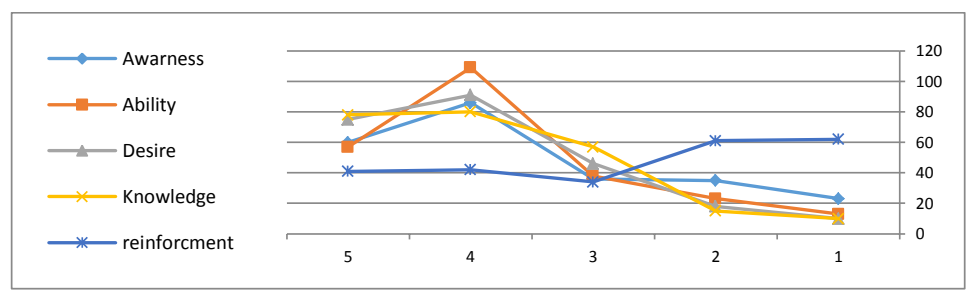

Figure 7.

Other dimension of change management process refers to work systems and process. Graph (7) shows statues of these variables. Must be told that besides of efficient workforce for successful in managing change process effectively, it is important that these changes be about organizations needs and opportunities, goals and boundaries of change must be defined, well developed organizations process and systems, provide well solutions and implementation of this solutions. Finally these solutions must be evaluated to show weaknesses and strengths. Figure (7) show statues of these factors in UT quality change process. This figure show that process and systems to do duties in UT don't developed suitably, needs and opportunities don't defined completely, goal of change in quality don't set clearly, and many solutions are in plan level only.

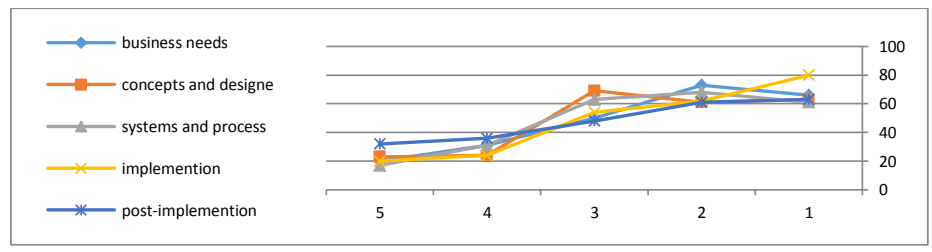

Figure 8. work dimension

\section{Conclusion}

Motwani (1995) cites that educational institutions have started to feel the pressure to change and reform. Furthermore, there is a belief that academic institutions that are slow to embrace TQM, at best, miss the opportunity to lead change and, at worst, run the risk of becoming less relevant to the business world. Nowadays all universities in all over the world oriented to quality and TQM. Lozier and Teeter (1996) reported that there are over 300 colleges and universities in US that are actively pursuing total quality principles. For 
success in this process universities utilize different policies. Moreland and Clark (1998) stated that teamwork, finding better ways to do things, sharing responsibility that are value set of many modern universities and their faculties are outcome of TQM orientation.

UT as an Iranian pioneer university tries in this field. In this paper we see that, change process (transformational or planned) need to have some circumstances. In this paper based on ADKAR model 2 set of factors were attended. UT should provide better support for change in quality, because other factors in the humanistic dimension are ready for change in quality. On the other hand university systems and process must be overview to successful in change process. This research proposed that, with regard to readiness of academic staff of UT for change in quality, University managers must provide other factors to successful change in quality of university.

\section{References}

ADKAR a model for change management. (2006). http//www.change management learning center.htm.

Bazargan, A. (1998). Quality evaluation in IRAN higher education. Quarterly Journal of Research and Planning in Higher Education, 1, 57-63.

Brigham, S.E. (1993). Lessons we can learn from industry. Change, 25 (3), $42-7$.

Burk, W.W. (2002). Organizations change theory and practice, SAGE publication, USA. pp63

Dalrymple, J. (2002). Developing a Holistic Model for Quality in Higher Education. online in http//www.cmqr.rmit.edu 2007.

Gourchian, N., et al. (2003). Higher education encyclopedia, 5, 7-11.

Kotter, J. (2007). Change phases . http//www.12manage.com.

Kruger. M. (2007). Change management iceberg, http//www.12manage.com.

Mirkamali, S.M. (2006). Educational matter for PH.D course.

Rangnes, K. and Haraldsen, K.B. (2007). Reform of the quality of higher education in Norway. http://www.ck-iv.dk.

Sarai, H.(1993). An introduction to research sampling Tehran SAMT publication. 14, 135141.

Unesco, (2007). HTTP//www.unesco.com.

Venkatraman, S. (2007). A framework for implementing TQM in higher education programs. Quality Assurance in Education, 15 (1), 92-112.

Zomorodian, A. (2006). Organizational change strategies, utilizations and new models. Industrial Organization Publication, 5, 130-135. 